Development and Psychopathology, 14 (2002), 107-122

Copyright (c) 2002 Cambridge University Press

Printed in the United States of America

\title{
Response decision processes and externalizing behavior problems in adolescents
}

\author{
REID GRIFFITH FONTAINE, ${ }^{a}$ VIRGINIA SALZER BURKS, ${ }^{b}$ \\ AND KENNETH A. DODGE ${ }^{a}$ \\ ${ }^{a}$ Duke University; and ${ }^{b}$ Vanderbilt University
}

\begin{abstract}
Externalizing behavior problems of 124 adolescents were assessed across Grades 7-11. In Grade 9, participants were also assessed across social-cognitive domains after imagining themselves as the object of provocations portrayed in six videotaped vignettes. Participants responded to vignette-based questions representing multiple processes of the response decision step of social information processing. Phase 1 of our investigation supported a two-factor model of the response evaluation process of response decision (response valuation and outcome expectancy). Phase 2 showed significant relations between the set of these response decision processes, as well as response selection, measured in Grade 9 and (a) externalizing behavior in Grade 9 and (b) externalizing behavior in Grades 10-11, even after controlling externalizing behavior in Grades 7-8. These findings suggest that on-line behavioral judgments about aggression play a crucial role in the maintenance and growth of aggressive response tendencies in adolescence.
\end{abstract}

Inquiry in social-cognitive psychology (e.g., Erdley \& Asher, 1996, in press; Fontaine, Burks, \& Dodge, 1998; Guerra, Nucci, \& Huesmann, 1994; Huesmann \& Guerra, 1997) and developmental psychopathology (e.g., Chandler \& Moran, 1990; Cicchetti \& Lynch, 1995; Dodge, 1993; Farrington, 1993; Fontaine \& Dodge, 1998; Rieder \& Cicchetti, 1989) has been directed toward understanding

This research was supported by the NIMH (NRSA Grant 1 F31 MH11764 to the first author) and the NICHD (Grant HD29816 to the second and third authors). We thank the students, parents, and staff of the Metropolitan Nashville Public Schools for their participation and Karen Swingly and Nicolas Nguyen for data management. We are grateful to Robert D. Laird, Stephanie E. Milan, David Schwartz, and Arnaldo Zelli for their insightful critiques of this paper. Special thanks are extended to Craig A. Smith for his repeated, unique contributions.

Address correspondence and reprint requests to: Reid Griffith Fontaine, Duke University, Psychology Department, Box 90085, Durham, NC 27708; E-mail: rgf2@ duke.edu. the association between cognitive processing and maladaptive social development. However, many researchers have continued to regard empirical attention to cognitive functioning and antisocial behavior in childhood and (especially) adolescence as insufficient (e.g., Garber, Quiggle, Panak, \& Dodge, 1991; Lochman \& Dodge, 1994; Shantz, 1983). One research area, in particular, that has continued to lack clarity involves the relation between evaluative decision processes (e.g., how individuals assess alternative courses of action) and aggressive social behavior (Fontaine \& Dodge, 1998; Guerra, Nucci, \& Huesmann, 1994; Huesmann, Guerra, Miller, \& Zelli, 1992). Research on adolescent social cognition may provide critical insight into the variability of developmental trajectories stemming from childhood into adulthood (see Allen, Weissberg, \& Hawkins, 1989; Inkeles \& Leiderman, 1996). In response to this concern, the present study focused on relations between behavioral decision making patterns and externalizing problems across the period from 
early adolescence (in Grades 7-8) to late middle adolescence (in Grades 10-11).

\section{Social Information Processing and Aggressive Behavior: The Response Decision Step}

Models of social information processing have played an instrumental role in developing our understanding of relations between cognition and aggressive behavior. Social information processing theory (SIP; Crick \& Dodge, 1994; Dodge, 1986; Huesmann, 1986, 1988) explains behavior in youth as the cumulative product of mental operations that are activated during social exchanges. According to a model of SIP advanced by Crick and Dodge (1994), children's social behavior in a specific situation operates via six cognitive processes. In response to a social stimulus, an individual (a) attends to selected stimulus cues and organizes incoming information (Step 1: encoding of cues), (b) makes social inferences and attributes characteristics (such as intent and causation) to the social stimulus and situation (Step 2: interpretation of cues), (c) realizes and specifies personal objectives (Step 3: clarification of goals), (d) generates alternative responses to the stimulus (Step 4: response access or construction), (e) evaluates alternative response styles (e.g., assessing expectations about possible outcomes) and selects the preferred response option (Step 5: response decision), and (f) carries out the selected behavioral response (Step 6: behavioral enactment). Although the degree to which children actually activate all of these processes during social interaction is likely to vary widely by individual and specific situation, several SIP processes, such as attributing hostility to others in ambiguously provocative social situations, have repeatedly been found to account for significant behavioral variance (e.g., Crick \& Dodge, 1994, 1996; Dodge \& Coie, 1987; Dodge \& Price, 1994; Waas, 1988; Waldman, 1996).

A central hypothesis of SIP is that youths who develop tendencies to process information in aggressogenic ways are more likely to engage in recurrent or chronic aggressive behavior. In turn, developing behavioral patterns may affect one's processing style. SIP has been instrumental in developing our understanding as to how complex, multivariate, reciprocal relations tie cognitive and behavioral processes together in an eternally changing social world. In this way, SIP may be of important utility to scientists who adhere to transactional models of human development. Transactional perspectives of development have conceptualized life adjustment as the continually changing product of ongoing, reciprocal interactions among a wide and varied array of internal and environmental factors (e.g., see Cicchetti \& Lynch, 1993; Cicchetti \& Rizley, 1981).

\section{The Response Decision Step}

The focus of the present study is on Step 5 of SIP, response decision, and how adolescents' tendencies to activate different response decision operations may contribute to the maintenance and growth of aggressive behavior. Originally, the response decision step was considered to embody processes that were primarily outcome focused: evaluating potential consequences of each alternative response, estimating the probability of favorable outcomes, and so forth (e.g., Dodge, 1986; Perry, Perry, $\&$ Rasmussen, 1986). This stage of processing has since been reformulated by Dodge and his colleagues (see Crick \& Dodge, 1994; Fontaine \& Dodge, 1999), and recent models of response decision have placed more emphasis on the potential role of means-based judgments about behaviors, such as "the moral acceptability of a response (how "good" or "bad" the behavior is judged to be)" and "selfefficacy judgments about the child's ability to enact a response" (Dodge, 1993, p. 569). Whereas outcome judgments focus on the potential or actual consequences of behavior, means-based judgments are evaluations of the actions and behavioral processes involved in social interaction (e.g., fighting, sharing). The present study was designed to examine two main components of the response decision step in adolescence: (a) assessing response options according to multiple evaluative criteria (such as social and moral acceptability and what consequences will result; called response evaluation), and (b) selecting a response for 
behavioral enactment (called response selection).

We hypothesized that adolescents who tend to evaluate their own aggressive responses favorably across various domains and to select aggressive responses for behavioral performance are more likely to develop and maintain aggressive behavioral styles. Although little research on SIP has focused on response evaluation and selection processes in adolescents, there exists direct and indirect empirical evidence linking positive evaluations and selections of aggressive response options with patterns of antisocial conduct in children and, to a lesser degree, adolescents. Compared to their nonaggressive peers, aggressive youths have been found to be more likely to (a) evaluate aggressive conduct as a type of social behavior that they feel confident in enacting (Crick \& Dodge, 1994; Erdley \& Asher, 1996; Perry et al., 1986); (b) endorse aggression as an appropriate, legitimate, "good," or "kind" style of social behavior (Deluty, 1983; Guerra \& Slaby, 1989; Slaby \& Guerra, 1988); (c) expect aggressive behavior to lead to favorable outcomes (Deluty, 1983; Guerra \& Slaby, 1989; Kennedy \& Perry, 1993; Lochman \& Dodge, 1994; Perry et al., 1986; Slaby \& Guerra, 1988); (d) minimize or devalue negative consequences of aggression such as victim suffering, victim retaliation, peer rejection, and loss of self-esteem (Boldizar, Perry, \& Perry, 1989; Kennedy \& Perry, 1993; Perry, Perry, \& Boldizar, 1990; Slaby \& Guerra, 1988); and (e) make response decisions that include aggression (Slaby \& Guerra, 1988; see also Crick \& Dodge, 1994).

Furthermore, Huesmann and his colleagues (Guerra, Huesmann, \& Hanish, 1994; Huesmann, 1986, 1988, 1996; Huesmann \& Guerra, 1997) have provided considerable supportboth theoretical and empirical-for the hypothesis that favorable evaluations and selections of aggressive behaviors are related to patterns of antisocial conduct. Huesmann's model of SIP proposes that, in responding to a social stimulus, an individual recalls (or accesses from memory) behavioral scripts that guide his or her response performance. Behavioral scripts serve as blueprints that contain both the procedural (e.g., what events are to occur) and declarative (e.g., how the person is to behave in response to these events) information that is needed in order to enact a response. Normative beliefs are the second type of cognitive structure that function to guide one's evaluation and selection of behavioral response options. Normative beliefs constitute a person's view as to how acceptable it is for him or her to carry out a particular behavior. Although empirical data on beliefs and judgments about aggression in youth are limited (Huesmann, Guerra, Zelli, \& Miller, 1992), cognitive schemas such as scripts and normative beliefs (e.g., Guerra, Huesmann, \& Hanish, 1994; Huesmann, 1996; Huesmann \& Guerra, 1997) have been found to account for variability in youth aggressive behavior. This finding provides support for the present hypothesis that response evaluation and selection styles favoring aggression are associated with externalizing problems throughout adolescence.

Specifically, the present study is focused on three main empirical questions. The first of these questions involves alternative conceptualizations of the dimensional structure of the response evaluation process. Dodge (1993) outlined six aspects of evaluation that have been hypothesized in past studies to influence response decisions in children. In Phase 1 of our investigation, we examine the interrelatedness of these six aspects in order to determine whether response evaluation is, according to the empirical data, more accurately characterized as (a) a multidimensional level of cognitive operating that embodies discernible evaluative processes, or (b) a unidimensional process. We hypothesized distinct processes of response valuation (i.e., valuing aggressive responses as acceptable along sociomoral lines) and outcome expectancy (i.e., anticipating positive outcomes for aggressing).

In Phase 2 of our investigation, we examined relations between aggressive-response decision processes (i.e., response evaluation and selection operations) measured in Grade 9 and externalizing behavior across time (in Grades 7-8 [T1], Grade 9 [T2], and Grades 10-11 [T3]). First, we tested hypotheses that selecting aggressive responses for behavioral performance (response selection) and that as- 
sessing aggression as more positive (or less negative) across multiple domains of response evaluation significantly account for variance in patterns of concurrent (T2) externalizing problems. Second, the relation between response decision processes at T2 and externalizing behavior at T1 and T3 was investigated. We were particularly interested in testing the incremental contribution of response decision processes at $\mathrm{T} 2$ in predicting from externalizing behavior in early adolescence (T1) to subsequent patterns of externalizing problems in late middle adolescence (T3).

Transactional models of developmental psychopathology have been established to explain maladjustment across the life course as the complex product of continuous, reciprocal interactions among numerous and varied psychological, social, and biological factors (e.g., see Cicchetti \& Lynch, 1993; Cicchetti \& Rizley, 1981; Cicchetti, Rogosch, \& Toth, 1997; Rieder \& Cicchetti, 1989). As time passes and the child interacts with his or her environment, factors and interactions that potentially contribute to the child's maturation undergo reorganization. By interacting with his or her environment, the child actively shapes his or her person-environment relationship (Sameroff \& Chandler, 1975). A transactional perspective of social cognition and aggressive behavior proposes that these variables are reciprocally causal and that they continually influence each other across time. Although we do not directly test a transactional model of cognition and aggression in this study, we examined the multivariate relation among T1 externalizing problems, T2 decision processing, and T3 externalizing behavior in order to determine if our results were in support of or opposition to this theoretical position.

We were also interested in exploring possible gender and race effects on processing and social behavior. Several studies have distinguished styles of aggressive behavior typical of boys from aggressive patterns more characteristic of girls (e.g., Crick \& Grotpeter, 1995; Lagerspetz \& Björkqvist, 1994). This suggests that, likewise, differences in aggressogenic processing may distinguish male from female youths. We also examined the possibility that processing styles may differ according to race.

\section{Investigation Phase 1: Factor Analysis of Response Evaluation Questions}

\section{Method}

Participants. The present study included a subset of adolescents who remained as participants (across Grades 7-11) in an ongoing longitudinal investigation of social development (ranging from Grades 1 to 12). At the outset of this longitudinal project (1986), parental consent was attained from approximately $80 \%$ of all children who were asked to participate (259 total: $48 \%$ female; $52 \%$ male; $40 \%$ African American; 60\% Caucasian). At that time, participants were in Grades 1, 2, and 3 of a public elementary school in the mid-South. Socioeconomic status varied across participants. In Grades 7-11, the following numbers of adolescent participants remained in the study: Grade 7, 195 (75\% of original sample); Grade 8, 181 (70\%); Grade 9, 166 (64\%); Grade 10, 150 (58\%); and Grade 11, 122 $(47 \%)$. Because the focus of this study is on the development of the relation between social-cognitive processing and externalizing behavior across adolescence, present analyses are based solely on adolescents who participated in the social information processing assessment in Grade $9(N=124 ; 52 \%$ female; 48\% male; $32 \%$ African American; $67 \%$ Caucasian; $1 \%$ other). There exist small differences in gender (48/52 in Year 1 vs. 52/48 in Grade 9) and race (40/60 in Year 1 vs. 32/67 in Grade 9) ratios when Year 1 and Grade 9 samples are compared. Analysis of Year 1 variables revealed no significant or otherwise notable differences between the original sample from Year 1 and samples at Grades 7-8, 9 , and 10-11.

Response decision assessment protocol. Participants watched a series of six video vignettes in which adolescent performers with formal drama training acted out diverse social interactions. The gender and race of the adolescent performers varied across vignettes. Participants watched the vignettes and were interviewed individually. Prior to each vignette, the investigator asked participants to imagine themselves as the protagonist in the interaction. In the first segment of each vignette, the 
protagonist suffers a negative outcome as the result of an ambiguous provocation by a peer or an adult. Vignette 2 serves as an example:

Students and teacher are appropriately seated in a classroom. Students are busy doing schoolwork while the teacher is writing quietly at his desk. A student (the protagonist) gets up from his seat to sharpen his pencil and starts to walk across the classroom toward the pencil sharpener. The teacher sharply asks the student what he is doing out of his seat.

In this case, the negative outcome for the protagonist is twofold-he is embarrassed due to being questioned by the teacher in front of his classmates, and he is obstructed from achieving his desired goal. Following each vignette, participants were asked how they would choose to respond to the portrayed event, representing the response selection process of response decision (the relations between response selection and other processing and behavioral variables are examined in Phase 2 of the investigation, below).

After the first segment of each vignette, participants were instructed: "If you were in this situation, there would be many things you could say or do. Let's look at [one] of these things." While still imagining themselves as the protagonist in the ongoing social exchange, participants watched a second segment of video in which the protagonist displays an aggressive response to the ambiguous provocateur. For example, in the second segment of $\mathrm{Vi}$ gnette 2, participants were requested to imagine themselves angrily responding: "If I don't sharpen my pencil, I can't take notes in your stupid class!" Participants then evaluated their reported aggressive response by answering questions representing possible domains of response evaluation.

Response decision variables. Descriptions of variables derived from the six individual response-evaluation questions follow. The alpha computed for each variable was based on the average score in response to a question across six varied vignettes. Mean scores were calculated to represent overall social-cognitive tendencies in order to relate such tendencies to antisocial behavioral patterns.
Response evaluation. After each aggressive response was presented, participants answered six questions intended to represent possible domains of response evaluation. Continuing with our example of Vignette 2, the six questions and domains (adapted and modified from Dodge, 1993) are (a) Would acting like this help keep your teacher from getting angry with you if you break the rules again? (instrumental outcome; $\alpha=.49$ ); (b) How much would your teacher like you if you acted like this? (interpersonal outcome; $\alpha=.49$ ); (c) How easy would it be for you to act like this? (efficacy and moral agency; $\alpha=.93$ ); (d) How would acting like this make you feel about yourself? (self-approval/intrapersonal; $\alpha=$ .85); (e) How much will others like you if they see you acting like this? (social acceptability/extrapersonal; $\alpha=.80$ ); and (f) Is this a good or bad thing to be doing or saying? (global valuation; $\alpha=.76$ ). Participants answered each question based on a 5-point scale ranging from a very negative (1) to a very positive (5) evaluation of the aggressive response. Mean scores were calculated across vignettes for each domain and the interrelatedness of the six domains was examined.

\section{Results}

Correlations among the six aggressive-response evaluation domains indicated two distinct groupings (see Table 1). Particularly strong relations were observed between domains 1 and $2 r=.46, p<.001)$ and among domains $3,4,5$, and 6 ( $r$ s ranged from .40 to .75 , each $p<.001)$. In addition, correlations between the first two domains and the last four domains were lower ( $r$ s ranged from .19 to $.39, p<.05$ ). These findings suggested the existence of two discernible components of response evaluation.

Factor analysis with oblique rotation ${ }^{1}$ revealed two unique underlying factors that to-

1. Oblique, as opposed to orthogonal, rotation was selected for factor analysis due to the significant correlations between aggressive-response evaluation domains. Consistent, significant correlations across these domains suggested that these domains, though conceptually distinguishable, were not empirically orthogonal or unique. 
Table 1. Correlations among domains of aggressive response evaluation

\begin{tabular}{lccccc}
\hline \multicolumn{1}{c}{ Domain $(\alpha)$} & 2 & 3 & 4 & 5 & 6 \\
\hline 1. Instrumental outcome (.49) & $.46^{* * *}$ & $.27 * *$ & $.19^{*}$ & $.19^{*}$ & $.24 * *$ \\
2. Interpersonal outcome (.49) & - & $.27^{* *}$ & $.26^{* *}$ & $.39 * * *$ & $.31^{* * *}$ \\
3. Efficacy and moral agency (.93) & & - & $.65^{* * *}$ & $.40^{* * *}$ & $.51^{* * *}$ \\
4. Self-approval/esteem (.85) & & & - & $.62^{* * *}$ & $.75^{* * *}$ \\
5. Social acceptability/extrapersonal (.80) & & & & - & $.55^{* * *}$ \\
6. Global valuation $(.76)$ & & & & & - \\
\hline \hline
\end{tabular}

${ }^{*} p<.05 .{ }^{* *} p<.01 . * * * p<.001$.

Table 2. Factor analysis of domains of aggressive response evaluation

\begin{tabular}{lrr}
\hline \hline & \multicolumn{2}{c}{$\begin{array}{c}\text { Factor } \\
\text { Loadings }\end{array}$} \\
\cline { 2 - 3 } \multicolumn{1}{c}{ Factor and Domain } & 1 & 2 \\
\hline Response valuation & & \\
$\quad$ Efficacy and moral agency & .74 & .19 \\
Self-approval/esteem & .93 & .07 \\
Social acceptability/extrapersonal & .73 & .22 \\
Global valuation & .85 & .15 \\
Outcome expectancy & & \\
Instrumental outcome & .10 & .86 \\
Interpersonal outcome & .23 & .81 \\
\hline \hline
\end{tabular}

gether accounted for $70.72 \%$ of the total variance. Results supported our initial conclusion that two different groups of domain variables existed. Table 2 presents factor loadings for the six response evaluation domains. Factor scores were computed based on unit weighting of item averages.

Factors were conceptualized as response valuation $(\alpha=.92 ;$ variance, $51.71 \%)$ and outcome expectancy $(\alpha=.64$; variance, $19.00 \%$ ), respectively (correlated at $r=.37, p$ $<.001$ ), representing a bidimensional model of response evaluation. The response valuation factor embodies means-based valuations and concerns common to social and moral behavior that may be considered prior to social responding (e.g., issues of moral agency, selfacceptance, and social appropriateness). The outcome expectancy factor includes judgments associated with the anticipation of attaining social desires and instrumental goals. Note that it is likely that comprehensive constructs of response valuation and outcome ex- pectancy include additional judgment criteria that are not captured by present assessment questions or derived-factor variables.

\section{Discussion}

In this phase of investigation, we empirically identified two domains (or processes) of response evaluation. The response valuation process represents means-based judgments about behavior, including considerations of social acceptability and sociomoral appropriateness, behavioral efficacy, moral agency, self-acceptance, self-affect (e.g., guilt, shame, pride, and sadness), and behavioral values. Outcome expectancy represents concerns about possible consequences of behavior, including social interests (e.g., social status and peer friendship) and instrumental goals (e.g., material possessions).

Response valuation and outcome expectancy processes may be considered in light of two trends of research on evaluative cognition and behavior. The first trend stems from studies of moral development in childhood (Kohlberg, 1963, 1964, 1984; Piaget, 1965) and has been based on the hypothesis that wrongful action (i.e., aggression) is the result of wrongful thinking (i.e., judgments endorsing harmful conduct), and perhaps vice versa (e.g., Bandura, 1991). Recent empirical examinations of moral reasoning and violence (Astor, 1994) and psychopathy (Chandler \& Moran, 1990) suggest there are different cognitive mechanisms by which aggressive-deviant youths understand the moral status of wrongful behaviors.

The second research trend has focused less on social and moral styles of reasoning and 
more on how interpersonal goals (Chung \& Asher, 1996; Erdley \& Asher, 1996), outcome values (Boldizar et al., 1989), and outcome expectancies (Perry et al., 1986) are related to conduct problem behaviors. For example, aggressive children anticipate more favorable outcomes to accrue from aggressing than do nonaggressive children (Crick \& Ladd, 1990). Furthermore, aggressive children have been shown to be less concerned by possible negative interpersonal outcomes (e.g., peer retaliation) and more interested in potential positive instrumental results (e.g., gaining control over a peer) of aggressive conduct (Boldizar et al., 1989; also see Deluty, 1983; Lochman \& Dodge, 1994). Instrumental and goal-oriented cognitive processes have been interpreted as causally related to aggression (Hart, Ladd, \& Burleson, 1990; Perry et al., 1986), based on the idea that individuals are motivated to behave in ways that they believe increase the likelihood of achieving desired outcomes.

\section{Investigation Phase 2: Relations Among Cognitive and Behavioral Factors}

The second phase of our investigation focused on multivariate, developmental relations among processing factors and behavior. As previously discussed, although this study was not designed specifically to test a transactional model of cognition and social behavior, data analysis was conducted with such a model in mind.

\section{Method}

Participants. Phase 2 of our investigation included all participants from Phase 1.

\section{Response decision variables.}

Response selection. Response selection was assessed by attaining the free response of each participant to the following question: What would you say or do if this happened to you? (Response selection was assessed following the first segment of each video vignette and prior to assessing response evaluation.) Responses were coded as either nonaggressive (1) or aggressive (2). Responses coded as ag- gressive included communications of both physical and verbal responses that were "violent, mean-spirited, hostile, or intimidating." These responses could reflect either direct aggression (e.g., "I would hit him") or indirect aggression (e.g., "I would tell my friends not to talk to her") but needed to exceed mere assertiveness.

Two graduate students (one psychology, one other) coded a random sample of 30 participants' responses $(N=124)$ with $97 \%$ agreement on type of response $(\kappa=.65)$. Intercoder differences were resolved by consensus and remaining responses were coded by one of the two trained coders. Scores representing participants' response selection styles were computed by averaging individuals' scores across vignettes $(\alpha=.42)$.

Response valuation and outcome expectancy. The unit-weighted average scores across the six vignettes were computed for response valuation (Questions 1 and 2) and outcome expectancy (Questions 3-6).

Measures of externalizing behavior problems. Adolescents' externalizing behavior problem scores were calculated by taking the mean score of the mother-reported Child Behavior Checklist (CBCL; Achenbach, 1991a, 1991b; assessed in Grades 7, $n=59 ; 8, n=58 ; 9, n$ $=75 ; 10, n=69$; and $11, n=67$ ) and the Youth Self-Report (YSR; Achenbach, 1991a, 1991c; assessed in Grades 7, $n=117 ; 8, n=$ $110 ; 9, n=123 ; 10, n=64$; and $11, n=81$ ) externalizing scale raw scores. These scores are based on the combination of aggression (bullies, fights, threatens, etc.) and delinquency (lies, steals, vandalizes, etc.) scale scores. Externalizing behavior was derived for three time points: the mean of Grades 7-8 (T1; $n=124)$, Grade 9 (T2; $n=124)$, and the mean of Grades $10-11$ (T3; $n=100) .{ }^{2}$ These

\footnotetext{
2. For Grades $7-8$ and $10-11$, the number of reports contained in the derived outcome variable ranges from two (one YSR score + one CBCL score or two YSR scores) to four (YSR and CBCL scores from Grades 7 and 8). For Grade 9, the number of reports contained in the derived outcome variable ranges from one (YSR or CBCL score) to two (YSR and CBCL scores).
} 
behavioral measures have been repeatedly established as having excellent reliability and validity. CBCL and YSR externalizing scores were correlated at $r=.78, p<.001$ (T1); $r=$ $.41, p<.001$ (T2); and $r=.35, p<.001$ (T3). It is important to note that CBCL and YSR scores are consistently significantly correlated across time points. Separate analyses revealed no significant differences in statistical relations between processing variables and CBCL versus YSR externalizing scores. That is, correlations between social-cognitive variables and behavior were consistent across source of reported behavior. No meaningful difference between sources of reported behavior with respect to our present examination was identified.

\section{Results}

Relations between response decision processes and externalizing behavior. Separate analyses of relations between processing variables and self-reported versus teacherreported adolescent behavior showed no significant differences; that is, findings did not differ significantly with respect to analyses of YSR versus CBC behavioral scores. As a result, YSR and CBCL indexes of externalizing problems were combined in order to derive a single composite index of externalizing behavior problems for each participant. The composite score was derived by taking the average of YSR and CBC scores for each participant. In the cases that had only one of the two possible scores, the recorded YSR or CBC score was used. The derivation of a single composite behavioral score allowed for all participants to be included in all analyses.

Means, standard deviations, and zero-order correlations for all response decision and externalizing behavioral variables are presented in Table 3.

Significant correlations were observed between response valuation and both response selection and outcome expectancy. Adolescents who evidenced tendencies to select aggressive behaviors as social responses or to expect positive outcomes to result from aggressing were more likely to make positive means-based judgments (or valuations) about their aggressive responses, relative to their peers. In contrast, response selection and outcome expectancy were not significantly correlated.

Grade 9 analyses showed that each component of response decision was significantly correlated with contemporaneous scores of externalizing behavior. The three response decision variables accounted for $30 \%$ of the variance in externalizing behavior problems. Furthermore, unique increments in the prediction of externalizing problems accrued from both response selection and response valuation (see Table 4).

This pattern of results was also observed upon relating Grade 9 processing variables to earlier externalizing behavior in Grades 7-8 (see Table 3). In addition, response decision processes were significantly predictive of $19 \%$ of the variance in Grades 10-11 externalizing behavior, with response valuation providing a unique increment in the prediction. These findings show that the tendency to valuate one's own aggressive responses favorably is associated with exhibiting conduct problems across all three time points in adolescence.

An additional goal of this study was to investigate the predictiveness of response decision processes in Grade 9 (T2) of later externalizing behavior in Grades 10-11 (T3), after controlling for earlier behavior in Grades 7-8 (T1). Table 5 shows results of a hierarchical regression predicting to $\mathrm{T} 3$ behavior in which T1 behavior was entered in Step 1 and the three T2 processing variables were entered in Step 2. A significant change in adjusted $R^{2}$ was observed, indicating that response decision processes incremented the prediction of T3 behavior from T1 behavior. This increment in prediction was clearly driven by the response valuation process as reflected by processing variable $\beta$ values. Furthermore, upon controlling for race and gender we observed no significant difference in the unique predictive increment provided by decision processing.

Effects of gender and race. Main effects of gender and race on processing and behavioral measures were examined. Regarding processing variables, moderate differences between 
Table 3. Response decision and externalizing behavior: Descriptives and correlations

\begin{tabular}{|c|c|c|c|c|c|c|c|}
\hline & $M$ & $S D$ & 2 & 3 & 4 & 5 & 6 \\
\hline \multicolumn{8}{|c|}{ Response decision processes $(n=124)$} \\
\hline 1. Response selection ${ }^{a}$ & 1.08 & 0.13 & $.29 * * *$ & .10 & $.32 * * *$ & $.32 * * *$ & .01 \\
\hline 2. Response valuation ${ }^{b}$ & 1.59 & 0.27 & - & $.37 * * *$ & $.51 * * *$ & $.54 * * *$ & $.42 * * *$ \\
\hline 3. Outcome expectancy ${ }^{c}$ & 1.96 & 0.55 & - & - & $.17 \dagger$ & $.20 *$ & .00 \\
\hline \multicolumn{8}{|l|}{ Externalizing behavior } \\
\hline 4. T1: Grades 7-8 $(n=124)^{d}$ & 11.17 & 6.32 & - & - & - & $.66 * * *$ & $.61 * * *$ \\
\hline 5. T2: Grade $9(n=124)^{e}$ & 12.26 & 7.55 & - & - & - & - & $.67 * * *$ \\
\hline 6. T3: Grades $10-11(n=100)^{f}$ & 9.94 & 7.20 & - & - & - & - & - \\
\hline
\end{tabular}

${ }^{a}$ Scale, 1.00-2.00; range, 1.00-1.83.

${ }^{b}$ Based on judgments of aggressive responses; range, 1.00-3.33.

${ }^{c}$ Based on judgments of aggressive responses; range, 1.17-2.42.

${ }^{d}$ Based on mean CBC-YSR raw score, Grades 7 and 8 combined; range, 1.00-36.00.

${ }^{e}$ Based on mean CBC-YSR raw score, Grade 9; range, 0.50-32.00.

${ }^{f}$ Based on mean CBC-YSR raw score, Grades 10 and 11 combined; range, 1.00-43.00.

$\dagger p<.06 .{ }^{*} p<.05 .{ }^{* *} p<.01 .{ }^{* * *} p<.001$.

Table 4. Simultaneous regression analyses predicting externalizing behavior in Grade 9 (T2) and Grades 10-11 (T3) from response decision patterns in Grade 9

\begin{tabular}{lll}
\hline \hline & \multicolumn{2}{c}{$\beta$} \\
\cline { 2 - 3 } \multicolumn{1}{c}{\begin{tabular}{c} 
Response Decision \\
\multicolumn{1}{c}{ Processes $^{a}$}
\end{tabular}} & \multicolumn{1}{c}{$\mathrm{T} 2$} & $\mathrm{~T} 3$ \\
\hline Response selection & $.18^{*}$ & -.10 \\
Response valuation & $.48^{* * *}$ & $.50^{* * *}$ \\
Outcome expectancy & .00 & -.16 \\
Adjusted cumulative $R^{2}$ & $.30^{* * *}$ & $.19^{* * *}$ \\
\hline \hline
\end{tabular}

${ }^{a}$ Based on evaluations of aggressive responses. $* p<.03 . * * * p<.001$.

female $(n=65)$ and male $(n=59)$ participants were found with respect to response valuation $(t=2.55, p<.05)$ and aggressive response selections $(t=2.41, p<.05)$. Male adolescents $(M=2.09)$ were somewhat more likely than their female peers $(M=1.84)$ to valuate aggression positively, and males $(M=2.11)$ tended to select more aggressive responses to social situations than did females $(M=2.05)$. Also, a moderate difference between African American $(n=40)$ and Caucasian $(n=83)$ participants was found with respect to response valuation $(t=2.19, p<.05)$, with African American participants $(M=2.11)$ somewhat more likely than their Caucasian peers $(M=1.88)$ to valuate aggressive responses favorably.
Behavioral rating differences were also observed with respect to gender at Grades 7-8 $(t=3.77, p<.001)$ and both gender $(t=2.30$, $p<.05)$ and race $(t=2.14, p<.05)$ at Grade 9. In Grades $7-8$, female $(M=9.23)$ participants displayed fewer conduct problems than males $(M=13.30)$. In Grade 9, as compared to their male $(M=13.87)$ and African American $(M=14.35)$ peers, female $(M=10.80)$ and Caucasian $(M=11.28)$ participants engaged in less externalizing behavior, respectively. No other significant gender or race main effects were observed.

Gender and race moderating effects were also investigated. Gender was observed to moderate the effect of aggressive response valuations on Grade 9 (males: $r=.65, n=59$, $p<.001$; females: $r=.35, n=65, p<.01$ ) and Grades 10-11 (males: $r=.60, n=43$, $p<.001$; females: $r=.18, n=57, n s$ ) externalizing behavior problems. Following the approach set out by Baron and Kenny (1986), hierarchical regressions were conducted in which externalizing problems were predicted from response valuation (independent variable) entered at Step 1, gender (moderator variable) entered at Step 2, and Gender $\times$ Response valuation (interaction variable, computed as the product of the independent and moderator variables after each had been centered at zero) entered at Step 3. The interaction between gender and response valuation significantly incremented (though moder- 
Table 5. Hierarchical regression analysis: Predicting externalizing behavior in Grades 10-11 (T3; $n=100)$ from externalizing behavior in Grades 7-8 (T1) and response decision patterns in Grade 9 (T2)

\begin{tabular}{lccc}
\hline \hline & $\beta$ & Adjusted $R^{2}$ & Adjusted $\Delta R^{2}$ \\
\hline Step 1 & & $.37 * * *$ & \\
T1 externalizing behavior & $.61^{* * *}$ & & \\
Step 2 & $.53^{* * *}$ & $.41^{* * *}$ & $.04 * * *$ \\
T1 externalizing behavior & & & \\
T2 response decision processes & & \\
$\quad$ Response selection & -.12 & & \\
$\quad$ Response valuation & $.26^{* *}$ & \\
$\quad$ Outcome expectancy & -.14 & \\
\hline \hline
\end{tabular}

${ }^{a}$ Based on evaluations of aggressive responses. $* * p<.01 . * * * p<.001$.

ately) the cumulative prediction of externalizing behavior in Grade 9 (change in adjusted $\left.R^{2}=.02, p<.06\right)$ as well as in Grades $10-11$ (change in adjusted $R^{2}=.04, \mathrm{p}<.05$ ). No other moderating effects were observed.

\section{General Discussion}

Phase 1 of this study revealed that response valuation of aggressive behavior represents a domain of response decision that is empirically distinct from outcome expectancy of aggression. In Phase 2, the tendency to valuate one's own aggressive behavior as a more positive (or less negative) style of social responsivity was found to be uniquely and consistently predictive of externalizing conduct problems across adolescent years. Furthermore, response valuation (Grade 9) incremented the prediction of externalizing behavior in later adolescence (Grades 10-11) from early adolescence (Grades 7-8). Our observation that adolescent valuation of aggressive responses accounted for externalizing behavior beyond that of earlier externalizing problems seems an especially notable finding given the fairly stable nature of antisocial behavior during this developmental period. These findings suggest that response decision patterns contribute to maintenance and growth in externalizing behavior problems during adolescence. This is an important contribution to a transactional perspective of social cognition and behavior that proposes that social- cognitive processing and behavior have a reciprocal causal relation across time.

Response valuation, outcome expectancy, and aggressive behavior

The consistent pattern of significant relations between processing factors (response selection, response valuation, and outcome expectancy) and behavior in Grades 7-9 provides initial support for the hypothesis that response decision processes play an important role in adolescent conduct problems. Although this pattern did not continue when response selection and outcome expectancy factors were correlated with future externalizing behavior in Grades 10-11, the relation between response valuation and externalizing problems was repeatedly robust across all adolescent time points. This finding is consistent with several related areas of research on values and aggressive behavior in youth. For example, Huesmann and Guerra (1997) found that normative (or internally consistent) beliefs that aggressive forms of behavior are socially acceptable and appropriate lead to growth in aggressive behavior across childhood. Relative to their nonaggressive peers, aggressive youths have been shown to view aggressive responsivity as "less morally bad" (Deluty, 1983), "more friendly" (Crick \& Ladd, 1990), and generally more acceptable (Asarnow \& Callan, 1985; Boldizar et al., 1989). Finally, positive evaluations of aggressive re- 
sponses have been linked to an increased probability of aggressive conduct in youth (Dodge, 1980).

Additionally, results indicate a manner in which externalizing versus nonexternalizing adolescents vary in their valuations of aggressive responses to ambiguously provocative social stimuli. Numerous studies on aggression have been based on procedures utilizing an approach by which ambiguous cues are presented in order to elicit competent versus antisocial reactivity (e.g., Dodge, 1980; Dodge \& Frame, 1982; Dodge \& Newman, 1981; Erdley \& Asher, 1996; Lochman \& Dodge, 1994; Waldman, 1996). Until present, such research has focused more on other components of social information processing, such as hostile attributional biases of deviant children and adolescents (e.g., Dodge \& Frame, 1982; Dodge \& Tomlin, 1987; Graham \& Hudley, 1994; Hudley \& Graham, 1993; Steinberg \& Dodge, 1983). Present findings suggest that, along with other factors characteristic of aggressive youths (such as hostile attributional biases), the tendency to valuate aggressive responses as sociomorally favorable is a strong positive correlate of externalizing outcomes.

The hypothesis that adolescents who expect aggressive responses to lead to desired outcomes also engage in more externalizing behavior was moderately supported. Previous studies have shown that aggressive youths believe aggressive responses are more likely to increase the number of favorable instrumental outcomes (Hart et al., 1990) and reduce adverse interpersonal outcomes (Quiggle, Garber, Panak, \& Dodge, 1992). Similarly, aggressive youths have been shown to expect aggressive acts to lead to more positive intrapersonal (i.e., favorable feelings about oneself) outcomes (Deluty, 1983) and the attainment of social goals (Perry et al., 1986). Present findings showed adolescents' outcome expectancies to be significantly (though moderately) related to externalizing behaviors in Grades 7-9 but not in Grades 10-11.

A possible reason that the outcome expectancy process was not more strongly associated with conduct problems is that motivational factors based on interpersonal goals and instrumental outcomes are more closely re- lated to a self-initiated style of aggressiveness called proactive aggression-or instrumental (e.g., Hartup, 1974) or offensive (Feshbach, 1997) aggression (see Dodge, 1991, for a review of proactive vs. reactive aggression). As opposed to reactive or retaliatory aggression, proactive-aggressive behaviors are exerted to facilitate one's control over another person or object (e.g., bullying). Crick and Dodge (1996) found that reactive-aggressive children do not assign higher instrumental utility to aggression than their peers, supporting the view that reactive aggression is not based on the expectancy that aggression leads to positive instrumental or interpersonal outcomes. The present study was designed to assess relations between reactive social-cognitive operations (i.e., mental operations in response to ambiguous provocations) and general patterns of externalizing behavior. Although the YSR and CBCL measure both reactive and proactive forms of externalizing behavior, it may be that in provocation situations such as the ones operationalized in this study, meansbased concerns about alternative behaviors are more predictive of antisocial behavior. Alternatively, outcome expectancy may be found to be more predictive of externalizing problems in studies designed to elicit proactive social-cognitive processes (e.g., identifying instrumental goals; see Crick \& Dodge, 1996). Another possible reason that a more robust effect of $\mathrm{T} 2$ outcome expectancy on $\mathrm{T} 3$ behavior was not found is the relatively lower internal consistency of the outcome expectancy variable. Whereas the response valuation variable was based on 24 items (four questions across six vignettes; $\alpha=.92$ ), the outcome expectancy variable was based on only 12 items (two questions across six vignettes; $\alpha=.64$ ), reflected by its relatively lower alpha value. The psychometric properties of the response selection variable may also explain why response selection at $\mathrm{T} 2$ $(\alpha=.42)$ did not correlate with externalizing problems at $\mathrm{T} 3$.

\section{A transactional perspective of response valuation and externalizing problems across adolescence}

Perhaps most interestingly, response valuation in Grade 9 was found to increment the predic- 
tion from early behavior in Grades 7-8 to later behavior in Grades 10-11. Adolescent style of valuating aggressive behaviors accounted for a portion of subsequent behavioral variability that is unique from and in addition to the variance accounted for by antecedent behavior measured only 2-4 years prior. This finding provides notable support for our hypothesis that response decision processes play a critical role in the formation and maintenance of developmental antisocial behavior in adolescence. It also suggests that the relation between response decision and aggression in adolescence is more complex than a possible alternative (but presently hypothetical) finding that merely shows processing and behavior to be consistently correlated across adolescent years.

The present study contributes to a more comprehensive explanation of social cognition and conduct problems in adolescence by supporting a conceptualization of the relation between behavioral decision processes and adolescent externalizing behavior that is guided by a transactional perspective (Sameroff \& Chandler, 1975; see also Cicchetti \& Richters, 1993; Cicchetti \& Toth, 1997). Transactional models of developmental psychopathology have been established to explain maladjustment across the life course as the complex product of continuous, reciprocal relations among numerous and varied psychological, social, and biological factors (e.g., see Cicchetti \& Lynch, 1993; Cicchetti \& Rizley, 1981; Cicchetti, Rogosch, \& Toth, 1997; Rieder \& Cicchetti, 1989). As time passes and the child interacts with his or her environment, factors and interactions that potentially contribute to the child's maturation undergo reorganization. By interacting with his or her environment, the child actively shapes his or her person-environment relationship (Sameroff \& Chandler, 1975).

A transactional perspective on adolescent aggression proposes that, although aggressive behavior is fairly stable during this developmental period, the reciprocal relation between social behavior and other factors (such as cognitive processing styles) also plays an important role. In the present study, adolescents' behavior predicted subsequent social-cogni- tive processing, which in turn was found to predict later externalizing problem patterns. In addition, cognitive processing added a unique increment in the prediction of subsequent behavior from antecedent behavior. These findings are consistent with a transactional view that social cognition and behavior serve as reciprocal causal influences upon each other across time.

The finding that response evaluation processes explain variability in adolescent externalizing behavior beyond that which may be accounted for by earlier behavior is consistent with the transactional view that aggressive adolescents may experience more interpersonal conflict as a direct and indirect result of their aggressive behaviors toward others. According to this perspective, not only do aggressive adolescents create conflict situations by acting in antisocial ways but, due to being involved in repeated conflict situations, develop a response decision tendency to valuate as acceptable (an example of how experience influences subsequent processing; see Cicchetti \& Lynch, 1995). In turn, this aggressogenic processing style contributes to the development and stability of aggressive adolescents' future conduct problems. In this way, an individual, by acting aggressively, may create an environment that is more hostile and conflict laden, serving to justify his or her valuation of aggression as appropriate and, in turn, promoting future performances of aggressive behavior. Over time, due to continued environmental conflict, adolescents' aggressogenic cognitive processing may become more automatic - and aggressive behavior more habitual (see Hart et al., 1990). Transactional models of human development emphasize the bidirectional necessity of the causal relation between social-cognitive processing and interpersonal behavior.

\section{On-line evaluative processes and latent cognitive structures}

Evaluations and judgments about aggressive behavior may take various cognitive forms and function in different ways. The present study investigated three decision processes that are hypothesized to be potentially active 
during the response decision step of social information processing. These processes are conceptualized as "on-line" cognitive operations (i.e., cognitions and mental operations as they are occurring). On-line cognitions are distinguished from secondary or latent mental structures such as inactive beliefs, attitudes, cognitive schemas, and values. Latent mental structures are off-line and stored at some level of memory until they are accessed for current use in on-line processing. Often, patterns of on-line processes reflect the contents of latent mental structures stored in memory. For example, a person's tendency to evaluate aggressive responses on-line as behaviors that are unacceptable may reflect his or her strong value that aggression is a wrongful way to act. In this way, a person's judgment tendency (e.g., valuating aggressive responses) may appear similar to his or her expressed value (e.g., a normative belief about aggression)that is, a pattern of on-line cognitions may act in accordance with latent cognitions stored in memory.

Present findings are based on on-line assessments of adolescents' reported social-cognitive responses to varied social situations. The method by which present data were collected dictates that results of this study be interpreted as discoveries about on-line cognitive processes, not latent mental structures. Although related, the present method and findings are quite different from methods and findings attributable to Huesmann and his colleagues (e.g., Huesmann \& Guerra, 1997) and other researchers of social cognition and aggression (e.g., Perry et al., 1986). Whereas Huesmann has found that aggressive youths hold normative beliefs (a type of latent mental structure or cognitive schema) that endorse aggressive behavior, the contribution of the present study is that, across varied social situations, aggressive adolescents were more likely to activate on-line processes by which they made positive means-based valuations of different aggressive responses.

Recently, advanced theoretical models of evaluative decision making (Fontaine \& Dodge, 1998) and social information processing (Huesmann, 1996) have directed scientific attention to behavioral judgment and decision processes (e.g, Erdley \& Asher, in press). In the process of doing so, the theoretical distinction between on-line cognitions and latent mental structures has been developed and new empirical methods have been proposed (see Fontaine \& Dodge, 1998). Ultimately, a methodological design may be used by which to test the potentially unique roles of on-line cognitions and memory structures in the development of social behavior.

The moderating effect of gender on the relation between response valuation and externalizing behavior

Aggression researchers have recently argued that it is the style, as opposed to the amount, of aggression displayed that best distinguishes boys' aggressive behavioral patterns from those of girls (e.g., Crick, 1997; Crick \& Grotpeter, 1995; Galen \& Underwood, 1997; see also Lagerspetz \& Björkqvist, 1994). Also, other research has found that girls hold different views as to the acceptability of aggressive actions (e.g., Huesmann, Guerra, Zelli, \& Miller, 1992). Although gender was found to have a main effect on $\mathrm{T} 1$ and $\mathrm{T} 2$ antisocial conduct, gender was also observed to have a moderating effect on the relation between response valuation of aggressive behavior (T2) and externalizing conduct at T2 and T3. The relation between response valuation and externalizing problems was significantly stronger for male adolescents than their female peers upon predicting to concurrent and subsequent behavior.

There may be multiple reasons why this moderating effect was observed. Response valuation may play a more prominent role in the aggressogenic cognitive processing and antisocial behavior of male youths than it does for females. It may be that response decision processing in girls is more characteristic of alternative processes such as outcome expectancy (although the interaction between gender and outcome expectancy did not increment the prediction of behavior in this study) or other judgment processes not yet ascertained.

Alternatively, because girls learn early in life that female aggression is undesirable 
and often viewed by others as unacceptable (Bandura, 1965; Huesmann, Guerra, Zelli, \& Miller, 1992), female participants' willingness to valuate aggressive responses favorably may have been somewhat attenuated, contributing to a less varied style of response valuation shared among females. A lesser degree of heterogeneity in females' response valuation scores may account (at least partially) for the stronger relation between male participants' valuation of aggressive responses and externalizing behavior.

\section{Conclusions}

The current study demonstrated convincing evidence of the critical role played by response valuation in adolescents' response decision style and conduct problem behaviors. Participants' valuations of their own aggressive responses in varied social contexts consistently predicted externalizing problem

\section{References}

Achenbach, T. M. (1991a). Integrative guide for the 1991 CBCL/4-18, YSR, and TRF profiles. Burlington, VT: University of Vermont, Department of Psychiatry.

Achenbach, T. M. (1991b). Manual for the Child Behavior Checklist/4-18 and 1991 Profile. Burlington, VT: University of Vermont, Department of Psychiatry.

Achenbach, T. M. (1991c). Manual for the Youth SelfReport and 1991 Profile. Burlington, VT: University of Vermont, Department of Psychiatry.

Allen, J. P., Weissberg, R. P., \& Hawkins, J. A. (1989). The relation between values and social competence in early adolescence. Developmental Psychology, 25, 458-464.

Asarnow, J. R., \& Callan, J. W. (1985). Boys with peer adjustment problems: Social cognitive processes. Journal of Consulting and Clinical Psychology, 53, 80-87.

Astor, R. A. (1994). Children's moral reasoning about family and peer violence: The role of provocation and retribution. Child Development, 65, 1054-1067.

Bandura, A. (1965). Influence of models' reinforcement contingencies on the acquisition of imitative responses. Journal of Personality and Social Psychology, 1, 589-595.

Bandura, A. (1991). Social cognitive theory of moral thought and action. In W. M. Kurtines \& J. L. Gewirtz (Eds.), Handbook of moral behavior and development: Vol. 1. Theory (pp. 45-103). Hillsdale, NJ: Erlbaum.

Baron, R. M., \& Kenny, D. A. (1986). The moderatormediator variable distinction in social psychological research: Conceptual, strategic, and statistical considerations. Journal of Personality and Social Psychology, 51, 1173-1182. patterns. Furthermore, response valuation incremented the prediction from externalizing behavior in early adolescence to later antisocial problems. These findings may be particularly useful in designing intervention programs that focus on cognitive-behavioral strategies toward preventing aggressive and delinquent behavior in youth. Results suggest that such programs might focus on adolescents' means-based judgments of the justifiability of aggressive behaviors and retaliation. Furthermore, this research has contributed to our knowledge of social information processing and behavioral competence in adolescence-a developmental stage that has received relatively little attention in this area compared to childhood or adulthood. Lastly, and perhaps most importantly, this study has brought us a step closer to understanding why it is that individuals develop and maintain tendencies to enact antisocial versus socially competent forms of interpersonal behavior.

Boldizar, J. P., Perry, D. G., \& Perry, L. C. (1989). Outcome values and aggression. Child Development, 60, 571-579.

Chandler, M., \& Moran, T. (1990). Psychopathy and moral development: A comparative study of delinquent and nondelinquent youth. Development and Psychopathology, 2, 227-246.

Chung, T.-Y., \& Asher, S. R. (1996). Children's goals and strategies in peer conflict situations. MerrillPalmer Quarterly, 42, 125-147.

Cicchetti, D., \& Lynch, M. (1993). Toward an ecological/ transactional model of community violence and child maltreatment. Psychiatry, 56, 96-118.

Cicchetti, D., \& Lynch, M. (1995). Failures in the expectable environment and their impact on individual development: The case of child maltreatment. In D. Cicchetti \& D. J. Cohen (Eds.), Developmental psychopathology: Vol. 2. Risk, disorder, and adaptation (pp. 32-71). New York: Wiley.

Cicchetti, D., \& Richters, J. E. (1993). Developmental considerations in the investigation of conduct disorder. Development and Psychopathology, 5, 331-334.

Cicchetti, D., \& Rizley, R. (1981). Developmental perspectives on the etiology, intergenerational transmission, sequalae of child maltreatment. New Directions for Child Development, 11, 31-55.

Cicchetti, D., Rogosch, F. A., \& Toth, S. L. (1997). Ontogenesis, depressotypic organization, and the depressive spectrum. In S. S. Luthar, J. A. Burack, D. Cicchetti, \& J. R. Weisz (Eds.), Developmental psychopathology: Perspectives on adjustment, risk, and disorder (pp. 273-313). Cambridge: Cambridge University Press.

Cicchetti, D., \& Toth, S. L. (1997). Transactional ecolog- 
ical systems in developmental psychopathology. In S. S. Luthar, J. A. Burack, D. Cicchetti, \& J. R. Weisz (Eds.), Developmental psychopathology: Perspectives on adjustment, risk, and disorder (pp. 317-349). Cambridge: Cambridge University Press.

Crick, N. R. (1997). Engagement in gender normative versus nonnormative forms of aggression: Links to social-psychological adjustment. Developmental Psychology, 33, 610-617.

Crick, N. R., \& Dodge, K. A. (1994). A review and reformulation of social information-processing mechanisms in children's social adjustment. Psychological Bulletin, 115, 74-101.

Crick, N. R., \& Dodge, K. A. (1996). Social informationprocessing mechanisms in reactive and proactive aggression. Child Development, 67, 993-1002.

Crick, N. R., \& Grotpeter, J. K. (1995). Relational aggression, gender, and social-psychological adjustment. Child Development, 66, 710-722.

Crick, N. R., \& Ladd, G. (1990). Children's perceptions of the consequences of aggressive behavior: Do the ends justify being mean? Developmental Psychology, 26, 612-620.

Deluty, R. H. (1983). Children's evaluations of aggressive, assertive, and submissive responses. Journal of Clinical Child Psychology, 12, 124-129.

Dodge, K. A. (1980). Social cognition and children's aggressive behavior. Child Development, 51, 162-170.

Dodge, K. A. (1986). A social information processing model of social competence in children. In $\mathrm{M}$. Perlmutter (Ed.), The Minnesota Symposia on Child Psychology: Vol. 18. Cognitive perspectives on children's social and behavioral development (pp. 77125). Hillsdale, NJ: Erlbaum.

Dodge, K. A. (1991). The structure and function of reactive and proactive aggression. In D. Pepler \& K. Rubin (Eds.), The development and treatment of childhood aggression (pp. 201-218). Hillsdale, NJ: Erlbaum.

Dodge, K. A. (1993). Social-cognitive mechanisms in the development of conduct disorder and depression. Annual Review of Psychology, 44, 559-584.

Dodge, K. A., \& Coie, J. D. (1987). Social-informationprocessing factors in reactive and proactive aggression in children's peer groups. Journal of Personality and Social Psychology, 53, 1146-1158.

Dodge, K. A., \& Frame, C. L. (1982). Social cognitive biases and deficits in aggressive boys. Child Development, 53, 620-635.

Dodge, K. A., \& Newman, J. P. (1981). Biased decisionmaking processes in aggressive boys. Journal of $A b$ normal Psychology, 90, 375-379.

Dodge, K. A., \& Price, J. M. (1994). On the relation between social information-processing and socially competent behavior in early school-aged children. Child Development, 65, 1385-1397.

Dodge, K. A., \& Tomlin, A. M. (1987). Utilization of self-schemas as a mechanism of interpretational bias in aggressive children. Social Cognition, 5, 280-300.

Erdley, C. A., \& Asher, S. R. (1996). Children's social goals and self-efficacy perceptions as influences on their responses to ambiguous provocation. Child Development, 67, 1329-1344.

Erdley, C. A., \& Asher, S. R. (in press). Linkages between children's beliefs about the legitimacy of aggression and their behavior. Social Development.

Farrington, D. P. (1993). Motivations for conduct disor- der and delinquency. Development and Psychopathology, 5, 225-241.

Feshbach, S. (1997). The psychology of aggression: Insights and issues. In S. Feshbach \& J. Zagrodzka (Eds.), Aggression: Biological, developmental, and social perspectives (pp. 213-235). New York: Plenum Press.

Fontaine, R. G., Burks, V. S., \& Dodge, K. A. (1998, March). The mediating effect of sociomoral judgments about aggression on the relation between hostile attributional style and antisocial conduct. Paper presented at the biennial meeting of the Conference on Human Development, Mobile, AL.

Fontaine, R. G., \& Dodge, K. A. (1999). On-line behavioral judgments and decision making in aggressive youth: A computational model of response evaluation and decision (RED). Manuscript submitted for publication.

Galen, B. R., \& Underwood, M. K. (1997). A developmental investigation of social aggression among children. Developmental Psychology, 33, 589-600.

Garber, J., Quiggle, N. L., Panak, W., \& Dodge, K. A. (1991). Aggression and depression in children: Comorbidity, specificity, and cognitive processing. In D. Cicchetti \& S. Toth (Eds.), Rochester Symposium on Developmental Psychopathology: Vol. 2. Internalizing and externalizing expressions of dysfunction (pp. 225-264). Hillsdale, NJ: Erlbaum.

Graham, S., \& Hudley, C. (1994). Attributions of aggressive and nonaggressive African-American male early adolescents: A study of construct accessibility. Developmental Psychology, 30, 365-373.

Guerra, N. G., Huesmann, L. R., \& Hanish, L. (1994). The role of normative beliefs in children's social behavior. In N. Eisenberg (Ed.), Review of personality and social psychology, development and social psychology: The interface (pp. 140-158). London: Sage.

Guerra, N. G., Nucci, L., \& Huesmann, L. R. (1994). Moral cognition and childhood aggression. In L. R. Huesmann (Ed.), Aggressive behavior: Current perspectives (pp. 13-33). New York: Plenum Press.

Guerra, N. G., \& Slaby, R. G. (1989). Evaluative factors in social problem solving by aggressive boys. Journal of Abnormal Child Psychology, 17, 277-289.

Hart, C. H., Ladd, G. W., \& Burleson, B. (1990). Children's expectations of the outcomes of social strategies: Relations with sociometric status and maternal disciplinary styles. Child Development, 61, 127-137.

Hartup, W. W. (1974). Aggression in childhood: Developmental perspectives. American Psychologist, 29, 336-341.

Hudley, C., \& Graham, S. (1993). An attributional intervention to reduce peer-directed aggression among African-American boys. Child Development, 64, 124138.

Huesmann, L. R. (1986). Psychological processes promoting the relation between exposure to media violence and aggressive behavior by the viewer. Journal of Social Issues, 42, 125-139.

Huesmann, L. R. (1988). An information processing model for the development of aggression. Aggressive Behavior, 14, 13-24.

Huesmann, L. R. (1996). The role of social information processing and cognitive schema in the acquisition and maintenance of habitual aggressive behavior. In R. G. Geen \& E. I. Donnerstein (Eds.), Human aggression: Theories, research, and implications for policy. New York: Academic Press. 
Huesmann, L. R., \& Guerra, N. G. (1997). Children's normative beliefs about aggression and aggressive behavior. Journal of Personality and Social Psychology, 72, 408-419.

Huesmann, L. R., Guerra, N. G., Miller, L., \& Zelli, A. (1992). The role of social norms in the development of aggression. In H. Zumkley \& A. Fraczek (Eds.), Socialization and aggression (pp. 139-151). New York: Springer-Verlag.

Huesmann, L. R., Guerra, N. G., Zelli, A., \& Miller, L. (1992). Differing normative beliefs about aggression for boys and girls. In K. Björkqvist \& P. Niemela (Eds.), Of mice and women: Aspects of female aggression (pp. 77-87). San Diego, CA: Academic Press.

Inkeles, A., \& Leiderman, P. H. (1996). An approach to the study of psychosocial maturity: The development of a cross national scale for adolescents. International Medical Journal, 3, 133-138.

Kennedy, E., \& Perry, D. G. (1993, April). Social-cognitive correlates of aggression and victimization. Poster presented at the biennial meeting of the Society for Research in Child Development, New Orleans, LA

Kohlberg, L. (1963). The development of children's orientation toward a moral order, I, Sequence in the development of moral thought. Vita Humana, 6, 11-33.

Kohlberg, L. (1964). Development of moral character and moral ideology. In M. L. Hoffman \& L. W. Hoffman (Eds.), Review of child development research (Vol. 1, pp. 383-431). New York: Russell Sage Foundation.

Kohlberg, L. (1984). The psychology of moral development. San Francisco: Harper \& Row.

Lagerspetz, K. M. J., \& Björkqvist, K. (1994). Indirect aggression in boys and girls. In L. R. Huesmann (Ed.), Aggressive behavior: Current perspectives (pp. 131-150). New York: Plenum Press.

Lochman, J. E., \& Dodge, K. A. (1994). Social-cognitive processes of severely violent, moderately aggressive, and nonaggressive boys. Journal of Consulting and Clinical Psychology, 62, 366-374.

Perry, D. G., Perry, L. C., \& Boldizar, J. P. (1990). Learning of aggression. In M. Lewis \& S. Miller (Eds.), Handbook of developmental psychopathology (pp. 135-145). New York: Plenum Press.

Perry, D. G., Perry, L. C., \& Rasmussen, P. (1986). Cognitive social learning mediators of aggression. Child Development, 57, 700-711.

Piaget, J. (1965). The moral judgment of the child. New York: Free Press.

Quiggle, N. L., Garber, J., Panak, W. F., \& Dodge, K. A (1992). Social information processing in aggressive and depressed children. Child Development, 63, 13051320.

Rieder, C., \& Cicchetti, D. (1989). Organizational perspective on cognitive control functioning and cognitive-affective balance in maltreated children. Developmental Psychology, 25, 382-393.

Sameroff, A. J., \& Chandler, M. J. (1975). Reproductive risk and the continuum of caretaking casualty. In F. D. Horowitz (Ed.), Review of child development research (Vol. 4, pp. 187-244). Chicago: University of Chicago Press.

Shantz, C. U. (1983). Social cognition. In J. H. Flavell \& E. M. Markman (Eds.), Handbook of child psychology (4th ed., Vol. 3, pp. 495-555). New York: Wiley.

Slaby, R. G., \& Guerra, N. G. (1988). Cognitive mediators of aggression in adolescent offenders: 1. Assessment. Developmental Psychology, 24, 580-588.

Steinberg, M. S., \& Dodge, K. A. (1983). Attributional bias in aggressive adolescent boys and girls. Journal of Social and Clinical Psychology, 1, 312-321.

Waas, G. A. (1988). Social attributional biases of peerrejected and aggressive children. Child Development, 59, 969-975.

Waldman, I. D. (1996). Aggressive boys' hostile perceptual and response biases: The role of attention and impulsivity. Child Development, 67, 1015-1033. 